\title{
MALACOPLAQUIA VESICAL CON AFECTACIÓN GANGLIONAR Y CURSO AGRESIVO
}

\author{
B. POZO MENGUAL, F.J. BURGOS REVILLA, G. BRIONES MARDONES, \\ A. LINARES QUEVEDO, M. GARCÍA-COSIO PIQUERAS*
}

Servicios de Urología y Anatomía Patológica*. Hospital Ramón y Cajal. Madrid.

Actas Urol Esp. 27 (2): 159-163, 2003

\section{RESUMEN}

“MALACOPLAQUIA VESICAL CON AFECTACIÓN GANGLIONAR Y CURSO AGRESIVO"

La malacoplaquia es un proceso inflamatorio granulomatoso crónico poco frecuente. En el tracto urinario es más frecuente en el sexo femenino, estando afectada la vejiga en el $75 \%$ de los casos. La extensión pélvica de la malacoplaquia es muy poco frecuente y aún menos frecuente es la afectación ganglionar a nivel pelviano y retroperitoneal. Se presenta el segundo caso en la literatura de malacoplaquia vesical con afectación extravesical y ganglionar pelviana.

PALABRAS CLAVE: Malacoplaquia. Ganglios linfáticos. Vejiga.

\section{ABSTRACT}

"BLADDER MALACOPLAQUIA WITH NODAL INVOLVEMENT AND AGRESSIVE COURSE"

Malacoplakia is an unusual chronical granulomatous disorder. In the urinary tract is more frequent in female, in 75 percent of cases involve the bladder. Pelvis extension of this disease is infrequent, and even less frequent is the involvement of pelvic and retroperitoneal lymph nodes. We present the second case in the literature of bladder malacoplakia with extravesical and pelvic node involvement.

KEY WORDS: Malakoplakia. Lymph nodes. Bladder.

$\mathrm{E}^{\mathrm{n}}$ 1902, Michaelis y Gutmann, describen un proceso inflamatorio granulomatoso, poco frecuente que afectaba fundamentalmente al tracto urinario inferior ${ }^{1}$. Un año más tarde, von Hanseman empleó el término "malacoplaquia", para definir este proceso, porque encontró en tres de estos pacientes la presencia de placas (plakos) blandas (malacos), de forma redondeada, de color amarillento o grisáceo, levemente sobreelevadas a nivel vesical ${ }^{2}$.

En un primer momento se pensó que afectaba en exclusiva a la vejiga, aunque en realidad puede comprometer a todo el tracto genitourinario, gastrointestinal, pulmones, piel, los huesos y los ganglios linfáticos mesentéricos.
En la literatura existen pocos casos registrados, siendo en la mayoría de las ocasiones procesos crónicos, aunque benignos y con relativa buena respuesta al tratamiento. Sin embargo, determinados casos de malacoplaquia se comportan de manera agresiva, con una elevada morbilidad y mortalidad.

La afectación extravesical con afectación de órganos vecinos, que incluso precisa de exenteración pelviana para controlar el proceso se ha descrito en la literatura ${ }^{3}$; sin embargo, la afectación ganglionar de la malacoplaquia sólo existe un caso descrito en la literatura ${ }^{4}$. Se presenta el segundo caso en la literatura de malacoplaquia vesical con afectación extravesical y ganglionar pelviana. 


\section{CASO CLÍNICO}

Mujer de 76 años remitida al servicio de Urología por el servicio de Gastroenterología ante el diagnóstico de posible tumor vesical infiltrante. La paciente presentaba síndrome constitucional marcado, con astenia y anorexia importantes, de meses de evolución asociado a dolor abdominal sordo, continuo en fosa iliaca izquierda, apreciándose a la exploración masa abdominal palpable en dicha región. La paciente no había presentado cambios en su hábito intestinal, no refería hematuria, ni infecciones del tracto urinario previas o antecedentes de urolitiasis.

La tomografía axial computarizada (TAC) abdomino-pélvica, objetivó la presencia de engrosamiento de la pared anterior y lateral vesicales sugestivas de neoformación, asociándose a la presencia de adenopatías retroperitoneales de tamaño significativo. En fosa iliaca izquierda se detectó una lesión hipodensa con captación parietal probablemente en relación con conglomerado adenopático con centro necrótico. No se evidenciaron metástasis hepáticas (Fig. 1).

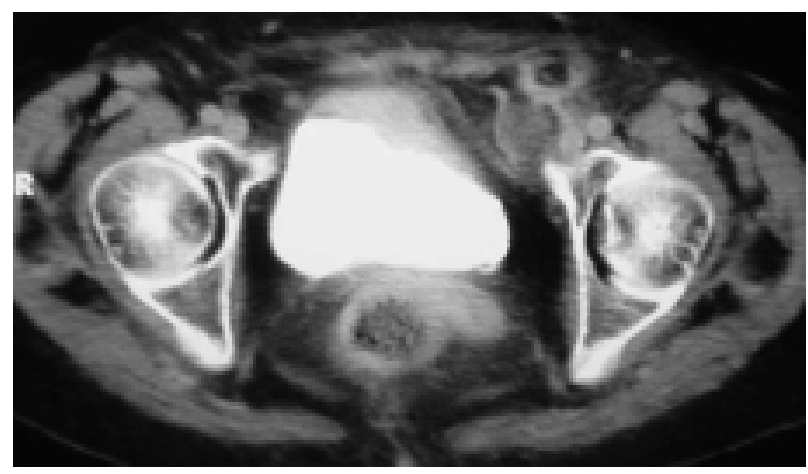

Figura 1. Imagen de TAC abdomino-pélvico. Se aprecia engrosamiento parietal vesical sugestivo de neoformación. En fosa iliaca izquierda se observa una lesión hipodensa con captación parietal probablemente en relación con conglomerado adenopático con centro necrótico.

Analíticamente presentaba leve anemia, creatinina dentro de límites normales, con sedimento de orina en el que se apreciaban 25 hematíes por campo sin bacteriuria. En la citología de orina se observaban alteraciones celulares de carácter inflamatorio.

Se realizó previo a resección endoscópica punción aspiración con aguja fina (PAAF) guiada por TAC de las adenopatías pélvicas sin evidencia de células tumorales y si abundantes leucocitos polimorfonucleares y detritos sugestivo todo ello de proceso inflamatorio agudo (Fig. 2).

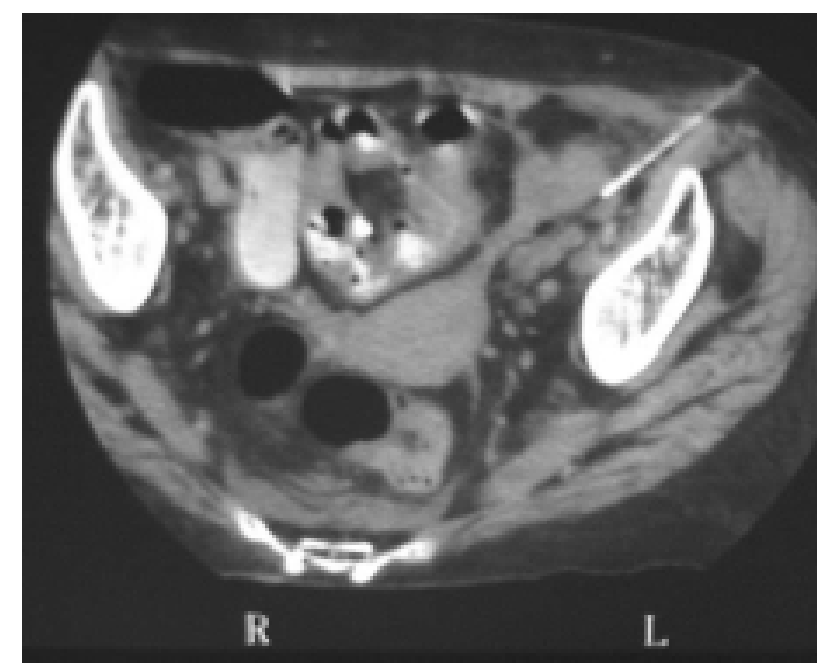

Figura 2. TAC+PAAF de lesión pelviana.

La Gammagrafía ósea no evidenció metástasis.

La exploración endoscópica bajo anestesia objetivó una lesión sobreelevada de aspecto mixto sólido-papilar de coloración amarillenta y base ancha en fondo y cúpula vesicales, llevándose a cabo resección endoscópica del crecimiento endovesical de la misma.

El estudio histopatológico reveló la presencia de un infiltrado histiocitario característico de malacoplaquia. La lesión fue negativa para malignidad (Figs. 3 y 4 ).

Con el diagnóstico de malacoplaquia vesical se inició tratamiento con ciprofloxacino $200 \mathrm{mg}$ iv/12 hs, aunque la paciente continuó deteriorándose, presentando importante astenia y anorexia.

Al décimoquinto día post-operatorio la paciente sufrió un cuadro de sepsis urinaria con hemocultivos positivos para staphylococos coagulasa negativos, con pancitopenia severa secundaria, falleciendo la paciente a las 48 horas.

\section{DISCUSIÓN}

La malacoplaquia es un proceso inflamatorio granulomatoso crónico poco frecuente, caracterizado histológicamente por la presencia de histiocitos de citoplasma claro (células de von Hansenmann) con inclusiones redondeadas intra- 


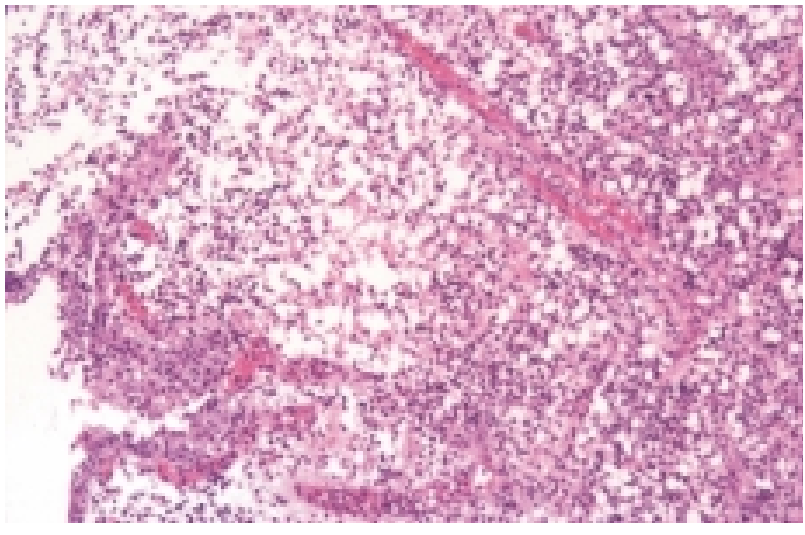

Figura 3. Imagen microscópica a 10 aumentos, tinción hematoxilina-eosilina (h-e). Se observa un infiltrado histiocitario difuso a nivel subepitelial.

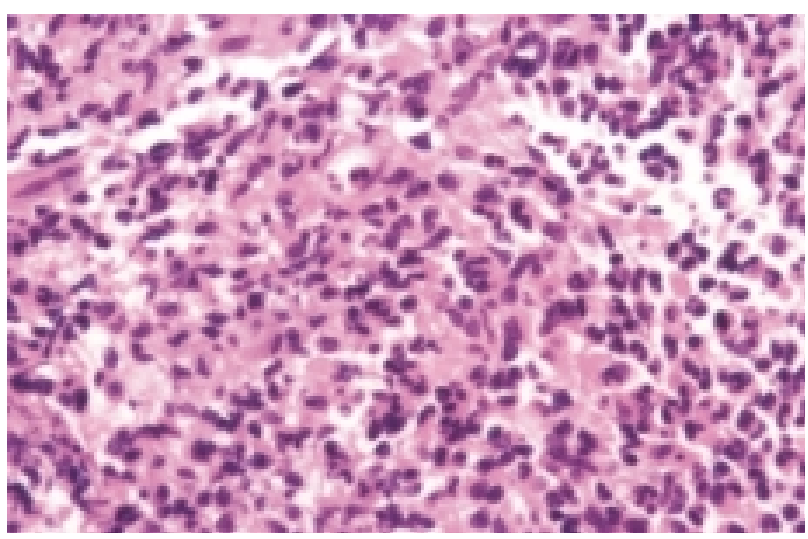

Figura 4. Imagen microscópica a 40 aumentos, tinción de h-e. Se aprecian histiocitos con citoplasmas voluminosos, acidófilos y granulares, presentando algunos de ellos cuerpos de Michaelis-Gutmann en su interior.

citoplásmicas muy características denominadas cuerpos de Michaelis-Gutmann. A nivel vesical, cursan macroscópicamente como placas sobreelevadas, friables de color amarillento, que en la mayoría de las ocasiones asemejan a un proceso tumoral ${ }^{5,6}$.

La malacoplasia en el tracto urinario es más frecuente en el sexo femenino con una relación (4:1), con una incidencia máxima en la quinta década, aunque puede presentarse a cualquier edad ${ }^{7}$.

En el $75 \%$ de los casos existe afectación vesical, seguido en orden descendente por el uréter, la pelvis y el parénquima renal ${ }^{1,2,4}$.

La enfermedad suele afectar a pacientes inmunodeprimidos, debilitados o con procesos crónicos (hepatopatías crónicas, diabetes, TBC y en tratamientos inmunosupresores) ${ }^{8}$.
La presentación clínica dependerá de la localización de la lesión. A nivel vesical predominan la hematuria macro o microscópica y síntomas irritativos miccionales de larga evolución. En el 80-90\% de los casos presentan urocultivos positivos para bacilos gram-negativos, de los cuales el $70-80 \%$ son por E. Coli ${ }^{1,8,9}$.

Con relación a la patogenia de la enfermedad existen varias teorías, aunque la mayoría coinciden en que existe una clara asociación de este proceso y la infección crónica por bacilos coliformes, acompañada en ocasiones de un estado general comprometido por enfermedades crónicas o inmunosupresión y de un defecto en la digestión bacteriana intralisosómica que dan lugar a las características inclusiones (cuerpos de Michaelis-Gutmann) intracitoplásmicas histiocitarias. Algunos autores consideran la presencia de un desequilibrio entre poblaciones de linfocitos T CD4-CD8, que daría lugar a una reducción del número de anticuerpos.

Otros autores indican la existencia de un déficit de GMPc (Guanosin monofosfato cíclico) a nivel histiocitario que sería el responsable de una digestión incompleta bacteriana, por lo que se ha propuesto como alternativa terapéutica el empleo de sustancias como el betanecol, un agonista colinérgico capaz de aumentar el nivel intracelular de $\operatorname{GMPc}^{5,7,10,11}$.

Las pruebas diagnósticas que orientan hacia el diagnóstico de malacoplaquia vesical, ante una paciente con clínica y urocultivos positivos para gérmenes coliformes sospechosa son:

Citología urinaria: es posible detectar la presencia de células con cuerpos de MichaelisGutmann.

Cistoscopia: aunque clásicamente se describe como característica la presencia de placas sobreelevadas de consistencia blanda y color amarillento, actualmente se describen 3 tipos o fases evolutivas ${ }^{12}$ :

- Nodular: que es la forma clásica asociada o no a ulceración o necrosis central.

- Ulcerada: lesiones con bordes sobreelevados y fondo amarillento.

- Pseudotumoral: lesiones verrucosas, elevadas con bordes hipervascularizados. 
Histológicamente las lesiones están constituidas, predominantemente, por colecciones de histiocitos con citoplasmas voluminosos, acidófilos y granulares (denominados células de Von Hanseman, que se disponen bajo el epitelio de superficie. En algunas de estas células pueden observarse inclusiones citoplásmicas redondeadas con disposición concéntrica (cuerpos de Michaelis-Gutmann), que son basófilas y PAS positivas.

Ultraestructuralmente se identifican bacterias coliformes intactas y fragmentos bacterianos en el interior de los fagolisosomas de los histiocitos de aspecto espumoso; sobre estos restos bacterianos se depositan sales férricas y sales de fosfato cálcico dando positividad para las tinciones de Pearls y von Kossa respectivamente $^{1,5,8,13}$.

En nuestro caso, la presencia de adenopatías retroperitoneales, así como una lesión hipodensa (baja captación en T1), nos sugería la presencia de una neoplasia vesical con afectación ganglionar. La accesibilidad de dichas lesiones permitió realizar PAAF, con estudio histológico compatible con proceso inflamatorio agudo que hizo pensar en la posibilidad de la malacoplaquia, aunque la afectación extraganglionar por malacoplaquia tuviera un carácter excepcional.

El pronóstico de la malacoplaquia suele ser favorable, aunque no siempre es un proceso benigno; en ocasiones, como en el caso que se presenta, existió una afectación extravesical y retroperitoneal, de carácter muy agresivo que provocó la muerte de la paciente. Afortunadamente la extensión pélvica de la malacoplaquia es muy poco frecuente. En la literatura urológica se han registrado menos de 10 casos de afectación extravesical y de órganos vecinos. Aún menos frecuente, como hemos visto es la afectación ganglionar a nivel pelviano y retroperitoneal $^{4}$. El tratamiento conservador en estos pacientes suele ser ineficaz, siendo en ocasiones necesaria la exanteración pelviana para resolver el cuadro ${ }^{3}$.

El tratamiento de la malacoplaquia localizada en el tracto urinario inferior suele ser conservador. Si el paciente presenta urocultivos positivos, la primera opción es el tratamiento prolongado con antibióticos que sean capaces de penetrar en el histiocito (gentamicina, cotrimoxazol, fluorquinolonas). Si el urocultivo es negativo, algunos autores apuntan el empleo de agentes anticolinérgicos como el betanecol, que aumenten los niveles de GMPc, potenciando la fagocitosis. También se ha propuesto el empleo de ácido ascórbico para potenciar el efecto de las enzimas bacteriolíticas, deficientes por los trastornos inmunológicos asociados ${ }^{14}$.

La asociación de resección endoscópica debe ser amplia y lo más temprana posible, por un lado permite eliminar grandes masas intravesicales, favoreciendo el tratamiento médico asociado y por otro es útil para la eliminación de posibles focos sépticos responsables de la infección crónica y el tratamiento de focos de hemorragia. En la mayoría de las ocasiones suele ser muy eficaz ${ }^{12}$.

En nuestro caso, la resección tuvo únicamente carácter diagnóstico, dada la extensión de la lesión.

Los casos de evolución favorable, deben revisarse de forma regular ante la posibilidad de recidiva, pues hay descritas recidivas a largo plazo.

\section{REFERENCIAS}

1. LONG JP, ALTHAUSEN F.: Malacoplakia: A 25-year experience with a review of the literature. J Urol 1989; 141: 1.328

2. O`DEA MJ, MALEK RS, FARROW GM.: Malacoplakia of the urinary tract: challenges and frustations with 10 cases. $J$ Urol 1977; 118: 739.

3. MATTHEWS PN, GREENWOOD RN, HENRY WF, CATTELL WR.: Extensive pelvic malacoplakia: observations on management. $J$ Urol 1986; 135: 132.

4. OLLIER P, BOURRIER P, ADIL A, ANIDJAR M, FRIJA J.: Malakoplakie vésicale et ganglionnaire: à propos d'un cas. J Radiol 2000; 81: 158-160.

5. STANTON MJ, MAXTED W.: Malocoplakia: a study of the literature and current concepts of pathogemesis, diagnosis and treatment. J Urol 1981; 125: 139.

6. LAGUNA URRACA G, TUDELA PATON MP, SOLERA SANTOS J.: Malacoplaquia vesical. Actas Urol Esp 1989; 13: 207.

7. McCLURE J.: Malacoplakia. J Path 1983; 140: 275.

8. CASTILLO JIMENO JM, GARCÍA HERREROS F, MOR GORROCHATEGUI C, JASO LÓPEZ AC, LÁZARO SANTANDER R, DOMINGUEZ ESCRIG JL.: Malacoplaquia vesical: a propósito de dos casos. Arch Esp de Urol 1998; 51: 183-185.

9. KAWAMURA N, MURAKAMI Y, OKADA K.: Three cases of malacoplakia of prostate. Urol 1980; 15: 78 . 
10. ZURIER RB, WEISSMANN G, HOFFSTEIN S, KAMMERSMAN S.: Mechanism of lysosomal enzyme release from human leukocytes. II. Effects of cAMP and cGMP, autonomic agonists, and agents which affect microtubule function. J Clin Invest 1974; 53: 297309.

11. OLKKONEN VM, IKONEN E.: Genetics defects of intracellular-membrane transport. $N$ Engl $\mathrm{J} \mathrm{Med}$ 2000; 343: 1.095.

12. VICENTE J, ALGABA F.: Macro y microscopía de las cistopatías (IV). Malacoplaquia vesical. Anales Fund Puigvert 1980; 10: 124.
13. SMITH BH.: Malacoplakia of the urinary tract, a study of 24 cases. Am J Clin Path 1965; 43: 409.

14. ZORNOW DH, LANDES RR, MORGANSTERN SL.: Malacoplakia of the bladder: efficacy of the bethanecol chloride therapy. J Urol 1979; 122: 703.

Dr. B. Pozo Mengual

Camilo José Cela, 4, portal 2 - 2ㅇ B

28230 Las Rozas (Madrid)

(Trabajo recibido el 17 de junio 2002)

\section{COMENTARIO EDITORIAL}

Los autores presentan un raro caso de malacoplaquia avanzado con desenlace funesto. En una reciente revisión ${ }^{1}$ amplia de malacoplaquias urinarias y extraurinarias expresábamos como una enfermedad teóricamente benigna, podía tener una evolución que acabara con la vida del paciente.

Aunque existen algunas dudas sobre si la aseptización de la orina de estos pacientes detiene la progresión de la enfermedad, existe bastante consenso en aplicar dicho tratamiento asociado a agentes colinérgicos $\mathrm{y}$ vitamina $\mathrm{C}$ como tratamiento de primera línea.

\section{REFERENCIAS}

1. BALLESTEROS JJ.: Malacoplaquia urogenital. Presentación de 4 casos y revisión de la literatura. Arch Esp Urol 2001; 54 (8): 768-776.

Fdo.: Dr. J.J. Ballesteros Sampol 